\title{
Innovation Computer Vision Technology With Internet Of Things (Iot) For Support Entrepreneurs In Fishery Sector
}

\author{
HELMY FAISAL MUTTAQIN, ARI PURNO WAHYU W
}

\author{
Fakultas Teknik, Universitas Widyatama \\ Email : Faisal.Muttaqin@widyatama.ac.id, ari.purno@widyatama.ac.id
}

\begin{abstract}
ABSTRAK
Sektor perikanan memerankan peran utama ke dua setelah migas, indonesia merupakan negara dengan wilayah laut yang luas di Asia Tenggara dan menjadi penghasil ikan nomor satu wilayah tesebut, produk -produk perikanan indonesia telah mampu bersaing dipasar domestik dan pasar internasional, sektor perikanan saat ini mencoba membuat sebuah sistem quality control atau kendali produk yang dihasilkan dari mulai level hulu dan hilir, besarnya jumlah produk ikan di Indonesia menjadi andalan penghasilan devisa negara, sumber perikanan indonesia berumber pada perikanan air tawar dan sumber perikanan air laut.
\end{abstract}

Agar mampu bersaing dipasar domestik diperlukan sebuah langkah dengan menjaga standar tempat pemeliharaan dan qualitas ikan, faktor qualitas ikan dipengaruhi dengan memperhatikan jenis pakan dan kualitas air, yang sangat berpengaruh pada habitat ikan tersebut, proses tersebut akan sulit jika dilakukan pada area yang luas serta menggunakan teknologi yang masih sederhana misalkan peternak ikan akan memberikan pakan ikan secara berkala dan manual mengecek keadaaan serta ukuran ikan yang masih menggunakan visual langsung, misalnya dengan mengukur bobot, kelengkapan tubuh ikan dan warna ukuran itu sendiri merupakan faktor yang sangat penting sebagai pengambilan keputusan bahwa ikan tersebut masuk kedalam kategori export atau tidak.

Untuk memudahkan monitoring kualitas ikan tersebut saat ini bisa menggunakan sebuah bantuan metode Computer vision dengan teknik image processing dengan implementasi teknologi IOT (Internet Of Thing), pada metode tersebut qualitas suhu air kolom dan ukuran kondisi ikan bisa monitoring bahkan menghitung kondisi jumlah ikan yang hidup dikolam, metode bisa mempersingkat waktu dan mengkover area habitat ikan dalam zona yang lebih luas dan menghemat tenaga serta biaya sehingga hasilnya dari produk ikan lebih optimal dan berkualitas

Kata kunci: Inovasi, Wirausaha, Computer Vision, Internet Of Thing. 
Innovation Computer Vision Technology With Internet Of Things (Iot) For Support Entrepreneurs In Fishery Sector

\section{PENDAHULUAN}

Sektor perikanan merupakan sumber mata pencaharian kedua setelah pertanian, sektor perikanan memiliki peranan sebagai penggerak perekonomian nasional dan mampu meningkatkan perekonimian keluaga yang meningkatkan ketahanan pangan pada skala nasional, derah penghasil budidaya ikan tersebar di beberapa derah Jawa dan Bali, sayangnya sektor tersebut belum dioptimalkan mengingat usaha perikanan ini masih dilakukam secara tradisional berbeda dengan sektor pertambangan dan pertanian sehingga sektor perikaanan kadang mengalami penurunan kualitas dan ekosistem tempat ikan dibudidayakan, sebagai langkah optimasi potensi sumber daya perikanan yang ada mengingat sektor perikanan menjadi syarat penggerak perkonomian nasional sesuai UUD no 17 tahun 2007 Rencana pembangunan jangka panjang, pada era computerisasi saat ini.

Sebuah solusi dengan bantuan sistem komputer diharapakan bisa membantu proses monitoritng dan sortasi ikan dan hitatnya tanpa merusak ecosistem ikan tersebut. Saat ini sebuah terobosan baru sudah dibuat oleh para ahli computer vision, dengan teknik tersebut telah banyak diimplementasikan di berbagai bidang yaitu pada industry, pertnian, pertambangan, dan petahanan. Teknologi tersebut bekerja dengan cara mengabungkan teknologi kompute dengan inputan dari sebuah camera, pada penelitian ini studi kasus yang diambil pada sektor perikanan pada proses sortasi ikan, dan monitoring air kolam itu sendiri yang akan berpangeruh pada pertumbuhan ikan, sebagai kasus suhu air yang terlalu dingin bisa mempengaruhi pertumbuhan ikan dan bisa menyebab ikan atau tubuh ikan menjadi luka dan cacat, serta ukuran dan aktifitas ikan manurun. Permasalahan tersebut bisa diatasi dengan bantuan camera yang akan memonitoring suhu kolam dan monitoring pertumbuhan ikan tersebut, algoritma computer vision akan menampilakan data perubahan air kolam,dan ukuran ikan tersebut secara alami dihabitat aslinya tanpa menyentuh dan merusak ekosistem ikan tersebut, teknologi ikan akan memangkas waktu dan biaya dan bermanfaat jika dimplementasi

\section{TINJAUAN PUSTAKA}

sebuah metode sederhana dengan menggunakan teknik observasi untuk mengamati dan menidentifikasi ikan dengan cara mengambil sample secara langsung dengan observasi dan pengambilan foto bawah laut atau penggunaan teknilogi sonar. [1]

metode lain untuk mengukur pertumbuhan ikan dengan cara mengambil sample ikan dalam keadaan mati, cara tersebut dapat merusak ikan dan habiatnya dan akan banyak menghabiskan waktu dan biaya, cara yang kedua adalah menggunakan teknik photography, metode tersebut yang bisa dilakukan secara acak dan bisa dilakukan dengan teknik observasi dengan mangamati ikan langsung dalam habitat asli dan alami. [2]

salah satu element yang penting dalam bidang perikanan dan kelautan adalah begaimana menggunakan sebuah teknologi yang bisa digunakan untuk menindentifikasi dan menggitung jumlah eksosistem ikan, masalah umum yang dihadapi adalah cara menggunakan Algoritma yang tepat yang akan menjadi dasar meningkatkan performance dalam melakukan sistem tracking pergerakan ikan dan proses perhitungannya. Algoritma yang handal mampu mengexplolasi data dan menghilangkan noise pada gambar inputan yang di ambil. [3]

Algoritma detection telah banyak diimplementasikan di banyak aplikasi sebagai langkah awal adalah penggunaan teknik computer vision memiliki banyak kehandalan dan telah banyak 
diuji coba untuk memonitoring pertumbuhan hewan secara akurat tidak banyak memakan waktu serta menggunakan kendali otomatis, pendekatan metode yang lain penggunakan pendeteksi objek yang menjadi dasar sism observasi perikanan. [4]

proses pendekatan algoritma computer vision ini bekerja dengan cara memodelkan tiap frame gambar yang diambil untuk menghindari resiko keselahan, jika target gambar memiliki warna yang sama dengan background, solusinya adalah dengan mangambil informasi objek berdasarkan tekture, kemudian Algoritma akan melakukan evaluasi semua informasi pada vidio yang diambil dibawah permukaan air dengan resolusi yang tinggi dan posisi yang stabil. [5]

pada peneltian sebelumnya penggunaan pengenalan pola sistem bisa digunakan untuk mengklasifikasikan jenis ikan termasuk ketagori beracun atau tidak melalui pengambilan sebuah data feature extraction digunakan untuk mengkalkulasikan ikan dari mulai lebar , tinggi , panjang tubuh ikan dan sudut kepala dan bagian tubuh lainnya, proses perhitungan Algoritma Neural Network untuk mengkalkulasi vareitas dan jenis ikan dengan akurasi $75 \%$ dan $95 \%$. [6]

$F(x, y)=$ It $x, y-B t(x, y)>T$

formula diatas digunakan untuk deteksi objek pada bagian background subtraction dengan nilai It sebagai frame masukan dan nilai Bt sebagai nilai background, sedangkan nilai $F$ adalah nilai objek bergerak yang terditeksi, deteksi utama dari sebuah objek adalah dengan menggunakan data tranformasi yang diambil disetiap frame, metode yang digunakan bisa disebut dengan metode temporal dengan mengurutkan semua bentuk frame saat penditeksian objek, dimana area sebuah frame akan ditandai secara dinamis yang akan dilacak pada setiap frame yang terbaca [?]

$0 \leq \mathrm{x} \leq \mathrm{M}-1$

$0 \leq \mathrm{y} \leq \mathrm{N}-1$

$0 \leq f(x, y) \leq \mathrm{G}-1$...(1)

Keterangan:

$M=$ jumlah suatu baris

$\mathrm{N}=$ jumlah pixel dalam warna

$\mathrm{G}=$ nilai derajat keabuan

citra digital memiliki sebuah nilai matrix yang terdiri dari beberpa kolom yang saling berpotongan yang bisa disebut sebagai pixel,yaitu sebuah elemen terkecil dari suatu citra, tiap pixel memiliki nilai koordinat yang merupakan gabungan dari intensitas warna yang disebut koordinat sumbu $(x, y)$ dan $f(x, y)$. [ $[$ ] 


\section{METODE PENELITIAN}

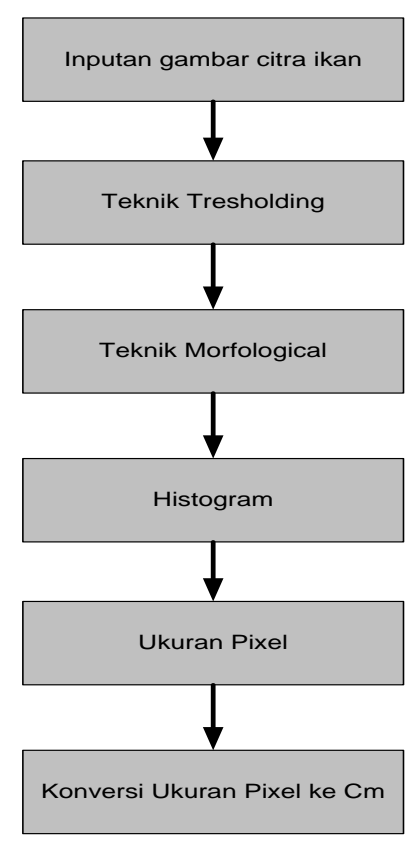

Gambar 1.1 metode diteksi ukuran ikan

Langkah metode penelitian

1. Inputan gambar ikan

pada metode ini gambar citra ikan Mas diambil menggukan kamera data sample yang diambil dari para peternak ikan yang dilihat ukurannya, gambar diambil pada posisi ikan sebalah kanan hal ini dimasukkan agar ukuran dari tubuh Ikan Mas bisa terpantau dengan jelas dari mulai bagian kepala hingga ekor.

\section{Teknik Treshoding}

Teknik tresholding berfungsi untuk menggambil posisi gambar utama ikan dan tidak terpengaruh oleh gambar lainnya, sebagai contoh gambar Ikan pada aquarium bisa menjadi noise karena posisi objek disekitar aquarium.

\section{Teknik Morfological}

Teknik ini digunakan untuk memantau perubahan objek pada citra ikan yang akan mempengaruhi ukuran ikan itu sendiri, dikarenakan terus bergerak pada aquarium sehingga setiap perubahan gerak akan mempengaruhi perubahan pixel ikan itu sendiri dan bisa mempengaruhi nilai ukuran ikan.

\section{Histogram}

Histogram pada sistem ini berfungsi untuk melihat indentitas jumlah pixel dari image ikan yang akan dikonversi menjadi $\mathrm{cm}$ (Centimeter). 


\section{Ukuran Pixel}

ukarn citra ikan yang digambarkan per layer dengan ukuran kedalam dari citra 0 -255 pengukuran pixel yang akan dikonversi ke bilangan $\mathrm{cm}$ dengan rumus pixels $* 2.54$ / 961 in $=2.54 \mathrm{~cm}$.

\section{Algortima konvers pixel ke "cm"}

pada gambar citra ikan yang telah dikonversi kedalam $\mathrm{cm}$, diambil pada tiap citra ikan dengan mengubahnya terlebih dahulu kedalam bentuk histogram pada teknik treholding dan "bw area" citra ikan dikonversi kembali sehingga nilai akurasi tidak meleset atau berubah.

\section{RANCANGAN SISTEM}

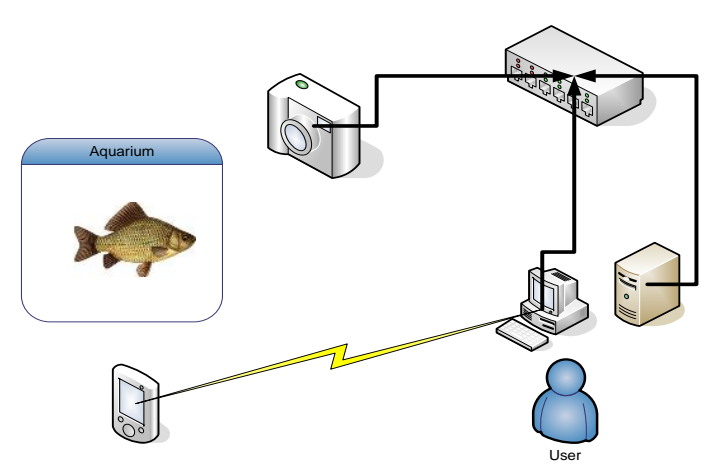

Gambar 1.2 Rancangan Sistem

Pada rancangan sistem diatas penulis menggunakan sistem aplikasi base on PC dimaksudakan agar proses percepatan data menjadi lebih cepat, gambar inputan diambil dengan menggunakan dua masukan yaitu melaui kamera yang dipasang langsung mengarah pada aquarium untuk memantau gerak ikan dan mengambil sudat yang bagus pada saat pengambilan objek atau bisa menggunakan kemera handphone yang dibuat secara mobile, data ikan kemudian dikirim ke PC untuk diproses manggukan Algortima Computer Vision dan data bisa disimpan pada databaser server agar bisa digunakan untuk penelitian selanjutnya, sebagai bahan acuan tentang ukuran dan proses perkembangan ikan, pada aquarium ikan sistem akan menggunakan metode treshhold agar data ikan dan background bisa dipisahkan jika pada gambar dengan jumlah ikan yang lebih banyak, pada sistem mobile gambar citra ikan bisa diambil secara acak pada jenis ikan yang berbeda dan tempat .

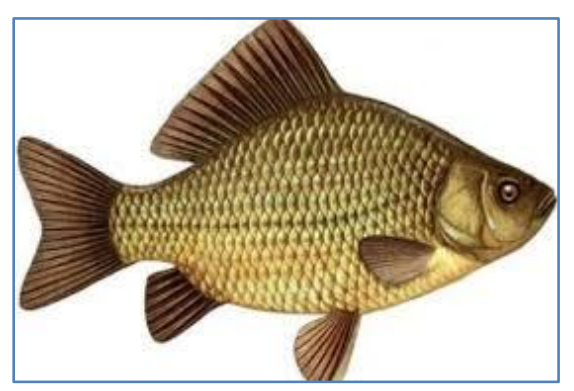

Gambar 2 citra ikan 
Innovation Computer Vision Technology With Internet Of Things (Iot) For Support Entrepreneurs In Fishery Sector

Pada gambar 2 (dua) diatas contoh citra ikan yang diambil pada bagian samping agar ukuran dari ikan bisa terlihat jelas dari ujung mulut hingga ekor dan tidak pada bagian atas

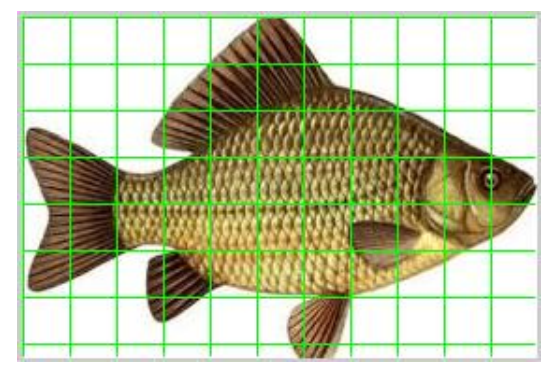

Gambar 3 aturan skala ikan dengan gridline

Pada gambar 3 merupakan pemasangan "grid line "yang dibuat secara visual menggunakan sistem yang berfungsi untuk membantu skala pengukuran dengan ukuran skala $1: 25$ ukuran skala otomatis akan berubah sesuai dengan ukutan pixel pada citra ikan

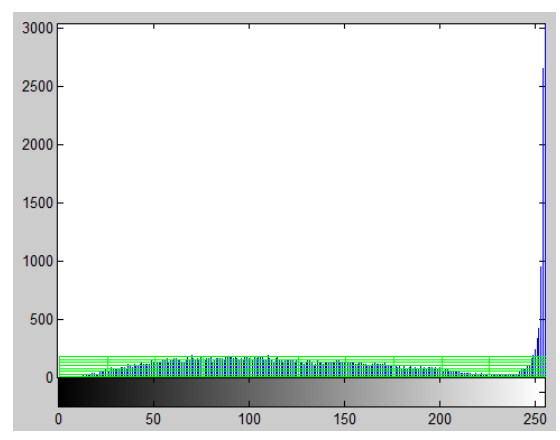

Gambar 4 citra histogram

Pada gambar 4 merupakan histogram yang merpresentasikan tampilan dari citra terhadap ukuran dari jumlah pixel dengan pengukuran skala warna 0- 255, pada tiap gambar ikan memiliki jumlah pixel yang berbeda-beda jumlah pixel ini yang nantinya akan dikalikan dan dirubah kedalam ukuran $\mathrm{cm}$

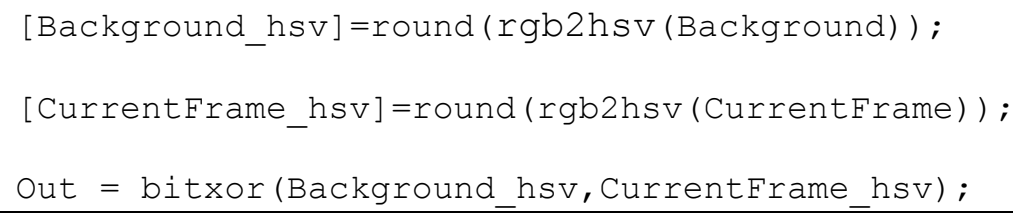

Gambar 5. Background subtraction

Keterangan : pada gambar 5 adalah proses pembacaan data dari inputan camera didasar air yang diambil per-frame kemudian diproses perframe dari setiap gambar ikan yang dimabil, dengan konsep memisahkan objek dengan derah pergerakan ikan, bahasa implementasi program di compile dalam bahasa " $\mathrm{C}$ " 


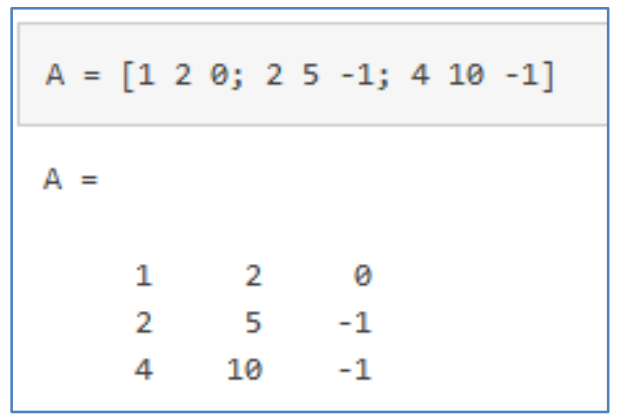

Gambar 6. Background Substraction

Pada gambar 6 setiap gambar yang diambil dari setiap frame akan di ubah keladalam bentuk biner sehingga data tersebut terpisah dari noise biner dan dikonversi kembali ke dalam bilangan matrik.

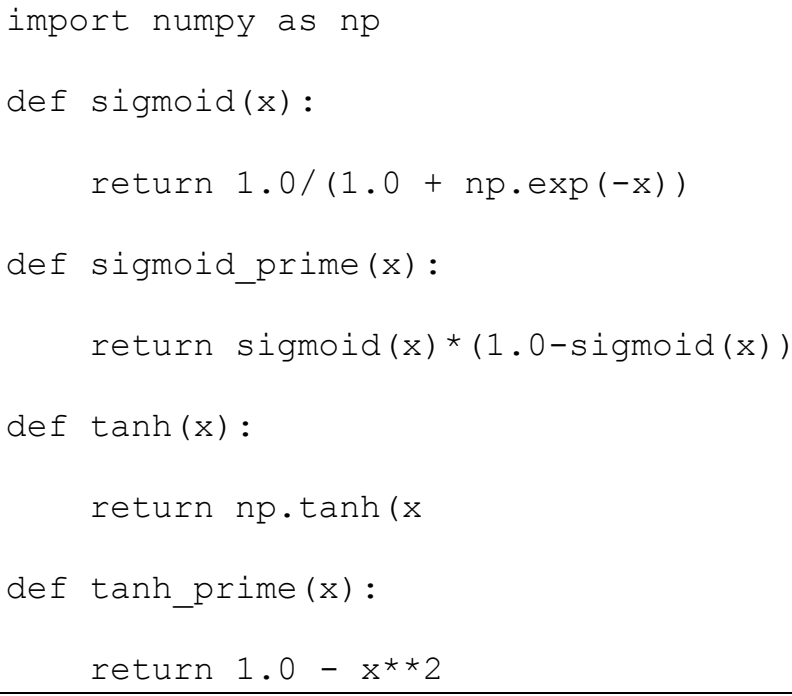

Gambar 7. Background Substraction

Pada gambar 7 sistem perhitungan jumlah ikan dengan menggunakan bahasa python programing dan yang digabungkan dengan algoritma neural network dengan beberapa masukan sigmoid dengan nilai variable masukan height,wide,long ,perubahan pada objek dengan mengambil ukuran tepi dari objek yang akan kan digunakan untuk mengambil skala ukuran yang tepat pada setiap perubahan pixel dari objek utama dalam aquarium yang dihitung secara realtime oleh sistem kemudian metode diteksi tepi berfungsi untuk melihat data objek ikan dikarenakan objek terus bergerak

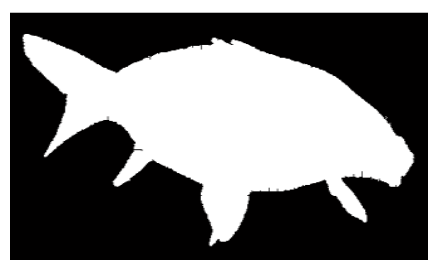

Gambar 8. bw area 
Pada gambar 8 adalah proses treshhold dengan misahkan warna dengan mengkonversi warna menjadi hitam putih denga mengguankan menu "bwarea" yang ada pada "oktave", bw area berfungsi untuk menghitung jumlah area pixel dari kesuluran objek tanpa dipengaruhi oleh noise pada gambar ikan

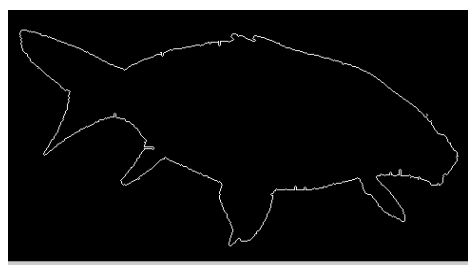

Gambar 9. morfological

Pada gambar 9 diatas yang itu konsep penggabungan antara morfologi dan ROI (Region Of interest ), fungsi morfologi adalah untuk mencatat setiap perubahan ukuran atau bentuk pada objek gambar dalam hal ini ikan ikan yang akan mempengaruhi nilai pengukuran.

\section{IMPLEMENTASI DAN PENGUJIAN}

Tahapan penelitian pada pengujian ini penulis menggunkan teknik yang disebut "PC on based system" atau teknik perangcangan kamera komputer vision yang sudah terintrgasi dengan PC agar kualitas data yang dihasilkan menjadi lebih cepat dibangdingkan dengan aplikasi mobile, pengambilan gambar citra ikan hanya digunakan pada bagian samping dan tidak mengambil keseluruhan citra ikan, hal ini dimasuka untuk mengambil sample ukuran dan bukan bobot dari ikan itu sendiri.

Tabel1.1 hasil pengujian sistem

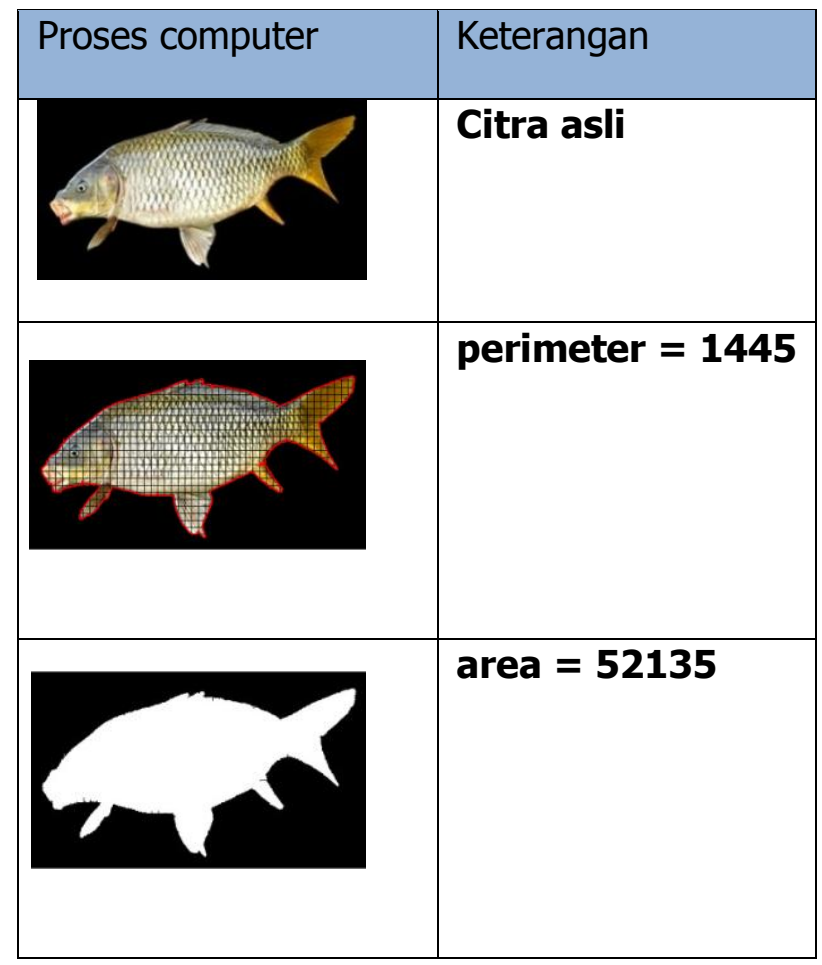




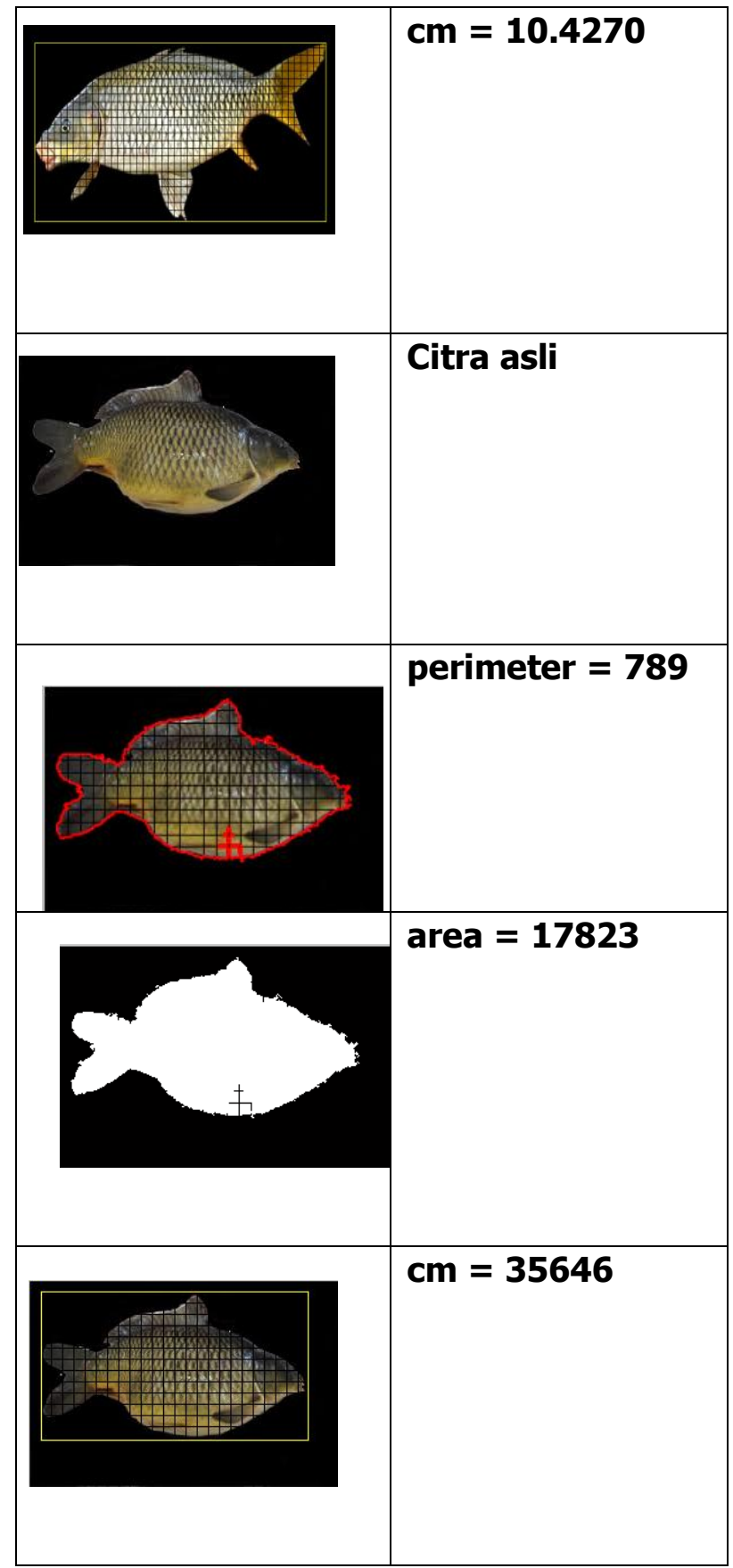

\section{PENUTUP}

Penerapan pada teknik computer vision untuk mengukur pertumbuhan ikan mas bisa dimplementasikan dengan menggunakan bantuan camera sebagai inputan gambar ikan yang diambil secara langsung. Pada kolam penampungan atau aquarium, ketepatan pengukuran masih tergantung pada kualitas kamera yang digunakan citra Ikan Mas akan dikonversi pada bentuk grayscale dan dikompersi dengan meggunakan teknik treshhold untuk memisahkan antara gambar utama dan citra ikan, hasil extrasi gambar tersebut berupa ukuran pixel kemudian menggunakan hitungan algoritma nilai citra ikan dikonversi kedalam bentuk $\mathrm{cm}$ ukuran pixel dengan formula centimeters = pixels $* 2.54 / 961 \mathrm{in}=2.54 \mathrm{~cm}$ sebagai contoh $3.25 * 2.548 .255 \mathrm{~cm}$. untuk penelitian kedepan bisa digunakan untuk perhitungan jenis ikan 
Innovation Computer Vision Technology With Internet Of Things (Iot) For Support Entrepreneurs In Fishery Sector

yang lain dan sistem pencahayaan yang harus diperhatikan yang akan mempengaruhi akurasi tangkapan gambar .

\section{DAFTAR RUJUKAN}

[1] Rouse W., ":Population Dynamics of Barnacles in the Intertidal," Marine Biology Research Experiment zone, may 2007.

[2] Yun-Heh Chen-Burger ; Gayathri Nadarajan ; Robert B. Fisher, "DETECTING ,TRACKING AND COUNTING FISH IN LOW QUALITY UNCONSTRAINED UNDERWATER VIDEOS," Department of Informatics and Telecommunication Engineering University of Catania.

[3] Rajagopalan N ; Burlina P ; Chellappa P., "Higher Order Statistical Learning for Vehicle Detection in Images ," Proceedings of ICCV99, pp. 20 -25, 1999.

[4] Violetta Shevchenko, "FISH DETECTION FOR SPECIES RECOGNITION," in FISH DETECTION FOR SPECIES RECOGNITION, Associate Professor Arto Kaarna and Professor Vladimir Pilidi, Eds.: Lappeenranta University of Technology , 2017.

[5] Simone Palazzo; Isaak Kavasidis ; Concetto Spampinato, "Covariance based modeling of underwater scenes for fish detection," In Proceedings of the 2013 20th IEEE International Conference on Image Processing (ICIP), pp. 1482-1485, 2013.

[6] Mutasem K Alsmadi;Khairuddin B Omar; Shahrul A Noah ; Ibrahim Almarashdeh, "Fish recognition based on robust features extraction from size and shape measurements using neural network," Journal of Computer Science, no. 10, p. 1088, 2010.

[7] Noor Wahyudi ; Vincent Suhartono ; Ricardus Anggi Pramunendar, "BACKGROUND SUBTRACTION BERBASIS SELF ORGANIZING MAP UNTUK DETEKSI OBJEK BERGERAK," SYSTEMIC, vol. 1, no. 1, pp. 45-51, Agustus 2015.

[8] Eka Ardhianto ; Wiwien Hadikurniawati ; Zuli Budiarso, "Implementasi Metode Image Subtracting dan Metode Regionprops untuk Mendeteksi Jumlah Objek Berwarna RGB pada File Video," Jurnal Teknologi Informasi DINAMIK, vol. 18, pp. 91-100, Juli 2013. 